\title{
Magnitude of non-adherence to antiretroviral therapy and associated factors among adult people living with HIV/AIDS in Benishangul-Gumuz Regional State, Ethiopia
}

\author{
Fikadu T Nigusso ${ }^{\text {Corresp., } 1,2}$, Azwihangwisi H Mavhandu-Mudzusi ${ }^{1}$ \\ ${ }^{1}$ Department of Health Studies, University of South Africa (UNISA), Pretoria, South Africa \\ Nutrition and Education Section, United Nations World Food Programme (WFP), Addis Ababa, Ethiopia \\ Corresponding Author: Fikadu T Nigusso \\ Email address: fikelf@gmail.com
}

Introduction. Following global efforts to increase antiretroviral therapy (ART) access and coverage, Ethiopia has made significant achievement with a 6.3\% annual decline in the HIV/AIDS incidence rate between 1990 and 2016. Such success depends not only on access to ART but also on attaining optimum treatment adherence. Emerging studies in Ethiopia has shown the increasing prevalence of poor adherence and lack of the desired viral suppression, but the extent and factors associated with nonadherence to ART are not well known, especially in the current study setup. In this study, we examined the magnitude and factors associated with treatment and non-adherence to ART among people living with HIV in Benishangul-Gumuz Regional State, northwest Ethiopia.

Methods. An institutional facility based cross-sectional descriptive study was carried out among adult people living with HIV/AIDS from mid-December 2016 to February 2017 with only 98.9\% response rate. Sociodemographic factors (age, gender, marital status and residential area), economic factors (educational status, income, asset possession, employment status, dietary diversity, nutritional status and food security), and clinical characteristics (CD4 count, duration on ART and history of opportunistic infections) were explanatory variables. ART non-adherence was measured using a visual analogue scale (VAS). We used binary logistic regression and subsequent multivariate logistic regression analysis to determine the factors associated with ART non-adherence.

Result. Overall, $39.7 \%$ of the participants were found non-adherent to ART. Strong association was found between non-adherence to ART and young age below 25 years (AOR: 4.30, 95\% Cl: 1.39, 3.35; $p=$ 0.011 ), urban residential area (AOR: $2.78, \mathrm{Cl}: 1.23,7.09, \mathrm{p}=0.043$ ), lack of employment (AOR: 1.75, 95\% Cl: 1.05, 2.91; $p=0.032$ ), food insecurity (AOR: $2.67,95 \% \mathrm{Cl}: 7.59,8.97 ; p<0.0001$ ), malnutrition (AOR: 1.55, 95\% Cl: 1.94, 2.56; $p=0.027$ ) and opportunistic infections (AOR: 1.81, 95\% Cl: 1.11, 2.97; $p$ $=0.018)$.

Conclusion. The prevalence of non-adherence to ART in this study was high. Sociodemographic and economic factors such as young age of below 25 years, urban residential area, lack of employment, food insecurity, malnutrition and opportunistic infections were among the factors associated with nonadherence to ART. 


\section{Magnitude of non-adherence to antiretroviral therapy and}

2 associated factors among adult people living with HIV/AIDS in

\section{Benishangul-Gumuz Regional State, Ethiopia}

4

5 Fikadu Tadesse Nigusso ${ }^{1,2}$, Azwihangwisi Helen Mavhandu-Mudzusi ${ }^{1}$

6

$7{ }^{1}$ Department of Health Studies, University of South Africa (UNISA), Pretoria, South Africa

$8{ }^{2}$ Nutrition and Education Section, United Nations World Food Programme (WFP), Addis Ababa, 9 Ethiopia

11 Corresponding Author:

12 Fikadu T. Nigusso

13 Email: fike1f@gmail.com

14

15

\section{ABSTRACT}

Introduction. Following global efforts to increase antiretroviral therapy (ART) access and coverage, Ethiopia has made significant achievement with a $6.3 \%$ annual decline in the HIV/AIDS incidence rate between 1990 and 2016. Such success depends not only on access to ART but also on attaining optimum treatment adherence. Emerging studies in Ethiopia has shown the increasing prevalence of poor adherence and lack of the desired viral suppression, but the extent and factors associated with non-adherence to ART are not well known, especially in the current study setup. In this study, we examined the magnitude and factors associated with treatment and non-adherence to ART among people living with HIV in Benishangul-Gumuz Regional State, northwest Ethiopia.

\section{Methods.}

An institutional facility based cross-sectional descriptive study was carried out among adult people living with HIV/AIDS from mid-December 2016 to February 2017 with only 98.9\% response rate. Sociodemographic factors (age, gender, marital status and residential area), economic indicators (educational status, income, asset possession, employment status, dietary diversity, nutritional status and household food security), and clinical characteristics (CD4 count, 
31 duration on ART and history of opportunistic infections) were explanatory variables. ART non-

32

33

34

35

36

37

38

39

40

41

42

43

44

45

46

47

48

49

50

51

52

53

54

55

56

57

58

59

60

61

adherence was measured using a visual analogue scale (VAS). We used binary logistic

regression and subsequent multivariate logistic regression analysis to determine the factors associated with ART non-adherence.

Result. Overall, 39.7\% of the participants were found non-adherent to ART. Strong association was found between non-adherence to ART and young age below 25 years (AOR: 4.30, 95\% CI: 1.39, 3.35; $\mathrm{p}=0.011)$, urban residential area (AOR: 2.78, CI: 1.23, 7.09, $\mathrm{p}=0.043)$, lack of employment (AOR: 1.75, 95\% CI: 1.05, 2.91; $\mathrm{p}=0.032$ ), food insecurity (AOR: 2.67, 95\% CI: 7.59, 8.97; $\mathrm{p}<0.0001$ ), malnutrition (AOR: 1.55, 95\% CI: 1.94, 2.56; $\mathrm{p}=0.027$ ) and opportunistic infections (AOR: 1.81, 95\% CI: 1.11, 2.97; $\mathrm{p}=0.018$ ).

\section{Conclusion.}

The prevalence of non-adherence to ART in this study was high. Sociodemographic and economic factors such as young age of below 25 years, urban residential area, lack of employment, food insecurity, malnutrition and opportunistic infections were among the factors associated with nonadherence to ART.

Keywords. adherence, antiretroviral therapy, HIV/AIDS, visual analogue scale

\section{INTRODUCTION}

Antiretroviral therapy (ART) has played a significant role in responding to HIV/AIDS epidemics (Granich et al., 2012; Williams, Lima \& Gouws, 2011). It has increased survival and improved quality of life, and reduced the rate of disease progression and death (Oguntibeju, 2012; Dalhatu et al., 2016). Consequently, ART service expansion has received significant support at the global and national level through the commitment of the Sustainable Development Goals (SDG) (UNAIDS, 2015; The Federal Democratic Republic of Ethiopia Ministry of Health, 2015). The SDG response sets out targets for HIV treatment: 90\% of people living with HIV know their HIV status, $90 \%$ of people who know their status receiving treatment and $90 \%$ of people on treatment having a suppressed viral load (UNAIDS, 2011). In line with this initiative, HIV treatment and care services have expanded dramatically (UNAIDS, 2018). In 2017, over 21.7 million people living with HIV were receiving ART globally (UNAIDS, 2018). Regardless of this increase,

Peer) reviewing PDF | (2019:08:39967:4:0:NEW 2 Jan 2020) 
62 ensuring adherence to HIV treatment remains challenging for the HIV/AIDS response, mostly in 63 sub-Saharan Africa (Fonsah et al., 2017; Eyassu, Mothiba \& Mbambo-Kekana, 2016; Wang et 64 al., 2011) including Ethiopia (Alagaw et al., 2013; Peltzer \& Pengpid, 2013).

65

66

67

68

69

70

71

72

73

74

75

76

77

78

79

80

81

82

83

84

85

86

87

88

89

90

91

92

Scientific literature indicates that for ART to be effective and prevent the emergence of resistant strains, a strict adherence level of $\geq 95 \%$ is recommended. This was based on Paterson's pioneer study that found up to $95 \%$ adherence is necessary for effective HIV viral suppression (Paterson et al., 2000). Once initiated, ART must be continued daily (World Health Organization, 2010). However, irrespective of the benefits of good adherence, not all people living with HIV/AIDS (PLWHA) fully adhere to the required treatment level. Failure to attain the required adherence level results in poorer prognosis, higher morbidity, mortality and the development of resistance to ART (Iacob, Iacob \& Jugulete, 2017; Nachega et al., 2011). Once resistance develops, it has dire consequences for individual PLWHA, family, community, healthcare providers and the healthcare system because treating ART resistant HIV strain requires second-line ART regimens, that are more expensive and have worse side effects (Chauhan et al., 2019; Karade et al., 2018).

Given the importance of adherence, a growing body of research has identified factors associated with non-adherence to ART as behaviors related to the patient itself, therapy related (medication regimens such as more than one tablet or dosing time per day and ART toxicity), poor relationships with healthcare providers and socioeconomic factors (Kim et al., 2018; Mohammed, Ahmed \& Tefera, 2015; Wasti et al., 2012). Poor ART adherence was reported among underprivileged communities where socioeconomic inequalities heighten the risk (Young et al., 2014) and lower quality of life is prevalent (Liping et al., 2015; Hansana et al., 2013), negatively impacting the HIV program (Wang et al., 2011). For PLWHA, factors related to gender dimensions, socioeconomic factors such as education status, income, asset possession and food security have been associated with non-adherence to ART (Basti et al., 2017; Abera et al., 2015; Alagaw et al., 2013). For example, in South Africa (Eyassu, Mothiba \& Mbambo-Kekana, 2016); Cameroon (Fonsah et al., 2017); and northern Tanzania (Samuel Edward et al., 2018), gender, income and level of education were reported as the determinants of ART adherence. Another study in Wolaita Sodo, Ethiopia, found lack of food was associated with poor adherence (Alagaw et al., 2013). In opposition to the culminated evidence, there are studies that have 
93 reported an absence of the impacts of socioeconomic inequalities on ART adherence in middle 94 and low-income countries (Peltzer \& Pengpid, 2013).

95

96

97 98

Ethiopia is among sub-Saharan African countries sturdily hit by epidemics. The country has made a significant achievement in responding to the HIV/AIDS epidemic, with a $6.3 \%$ annual decline in the HIV/AIDS incidence rate between 1990 and 2016 and a total reduction of 77\% (Deribew et al., 2019). Regardless of the government's commitment to end the HIV/AIDS epidemic as per the 2030 SDG initiative (particularly that envisages a 90\% suppression of viral loads to prevent treatment failure and reduce AIDS-related deaths), achieving the required level of suppressed viral load is becoming a challenge in Ethiopia. Current evidence in the country has shown that only $32 \%$ of PLWHA on ART have suppressed viral loads (UNAIDS, 2017). Studies have indicated that lack of viral suppression is an indication of non-adherence to ART (Byrd et al., 2019; Nasuuna et al., 2018; Robbins et al., 2014). Therefore, understanding the level of adherence and factors related with non-adherence helps to prevent the future threat of widespread treatment resistant HIV strains. We, therefore, aimed at investigating the magnitude and associated factors with non-adherence to ART among adult people living with HIV and on treatment in Benishangul-Gumuz Regional State (hereafter Benishangul-Gumuz) in northwest Ethiopia. Our results will inform implementation of strategic programs and practices to improve ART adherence to achieve optimal HIV care in the country.

\section{METHODS}

\section{Study design and population}

A cross-sectional study was conducted from mid-December 2016 to February 2017 in Benishangul-Gumuz, one of the nine regional states of the Federal Democratic Republic of Ethiopia located in the northwestern part of the country. The study was conducted among two referral hospitals and three health centers which provide comprehensive HIV care services. These health facilities were purposely targeted as they are utilized by the majority of people living with HIV. During this study period, there were a total of 2,721 PLWHA who were on ART treatment follow-up among the selected facilities. Sample size for this study was determined using the formula for the estimation of single proportion, $\mathrm{n}=\frac{(\mathbf{z})^{2} \boldsymbol{p}(\mathbf{1}-\boldsymbol{p}}{\boldsymbol{d}^{2}}$, where proportion (p) of $63 \%$ taken from the previous study in Ethiopia (Tiyou et al., 2012) margin of 
124 error $(d)=5 \%$, and $95 \%$ confidence limit $(Z=1.96)$. By adding $10 \%$ to cater for non-response 125 rate, a total of 394 respondents were enrolled into the study. This was allotted to the study sites 126 proportionally to the number of case load at each facility. Finally, a simple random sampling 127 technique using a sampling frame developed from the registration book of the patients was used 128 to enrol respondents daily at each study sites. The study entry criteria were: (a) PLWHA who 129 had received at least one-month antiretroviral therapy and on follow-up at the selected health 130 facilities, and (b) resided in Benishangul Gumuz Regional State for at least two years, (c) signed 131 consent to participate in the study. Exclusion criteria: (a) below 18 years of age, (b) critically ill, 132 (c) psychiatric health problem as previously diagnosed and confirmed. Table 1 presents the 133 number of accessible populations or PLWHA receiving ART during the study period and sample 134 contribution among the study sites.

135

136 Data and measures

137 A structured questionnaire was used for face-to-face interviews with the study population during 138 times participants were waiting to see ART service providers and for pharmacy refills. The study tool was checked for clarity and consistency among the selected health facilities out of the study sites by a group of health providers over a two-week period. The result assisted in ensuring the quality and consistency of the instrument. Training was given to data collectors about the objectives of the study, and how they could approach the patients to obtain their confidentiality.

143 The collected data kept in locked cabinets and password protected computers during data processing and analysis. Data extraction forms were reviewed daily for completeness. The questionnaire contained different variables such as sociodemographic and economic characteristics, clinical and anthropometric information.

\section{Antiretroviral therapy adherence}

149 Antiretroviral treatment adherence is the level to which a person is taking medicine as prescribed 150 by a physician and as per medical recommendations in relation to timing, dosing and consistency, and correctly taking the drugs in terms of right doses and right times (Chaiyachati et al., 2014). In this study, patient self-assessments were collected using the visual analogue scale (VAS) to measure primary outcome and adherence. VAS method was used to assess the adherence mostly in resource-limited settings and the most effective and feasible method 
155 available at the time the study, and shown to predict virological response in clinical trials and 156 clinical routines (Finitsis et al., 2016; Chkhartishvili et al., 2014). With the VAS approach, a 157 series of scales with values ranging from 0 to $100 \%$ is used to assess adherence during the past

15830 days (Chesney et al., 2000). The participants were asked to place an " $X$ " inside the box above 159 the point showing the best guess about how much of their current antiretroviral medications were 160 taken in the past 30 days. Adherence at a VAS score of $\geq 95 \%$ over the past 30 days was defined 161 as adherent and less than $95 \%$ as non-adherent.

162

163 Outcome measures

164 To investigate the extent and factors associated with non-adherence to ART among people living 165 with HIV and on treatment, we used socioeconomic indicators such as education, income, asset 166 possession, employment status, dietary diversity, nutritional status and household food

167

168

169

170

171

172

173

174

175

176

177

178

179

180

181

182

183

184

185 insecurity. Sociodemographic characteristics such as age, gender and marital status; clinical characteristics such as CD4 count, duration on ART and history of opportunistic infections were taken into consideration during the interviews and chart review for data collection. Inclusion of independent variables were based on literature reviews conducted, data availability, and theoretical relevance (Tabachnick \& Fidell, 2007). We chose these independent variables because of extensive literature highlighting the relationship between these covariates and ART adherence (Fonsah et al., 2017; Eyassu, Mothiba \& Mbambo-Kekana, 2016; Alagaw et al., 2013; Peltzer \& Pengpid, 2013; Bangsberg, 2006).

Food insecurity is defined as the economic and social condition of limited or uncertain access to adequate food (US Department of Agriculture, Economic Research Service, 2019). The access component of household food insecurity was measured using the standard household food insecurity access scale (HFIAS) (Coates, Swindale \& Bilinsky, 2007). This is a nine-item questionnaire assessing household food insecurity in the domains of anxiety about household food access, insufficient quality of food and insufficient food intake in the past 30 days. In this study, HFIAS was calculated by summing the score for all nine items and ranges from 0 to a maximum of 27. A higher HFIAS score indicates poor access to food and greater food insecurity. Respondents were assigned to discrete categories of food insecurity severity: 1) food secure, 2) mildly food insecure, 3) moderately food insecure, and 4) severely food insecure, which we

Peer) reviewing PDF | (2019:08:39967:4:0:NEW 2 Jan 2020) 
186 dichotomized into food insecure versus food secure. The alpha value for internal consistency of 187 the scale was 0.91 .

188

189 Malnutrition is the condition that occurs when the body does not get enough nutrients (US 190 National Library of Medicine, 2019). In this study, malnutrition refers to undernutrition. The 191 researchers used anthropometric measurement such as weight and height to measure 192 malnutrition. The participants' weight was measured by means of the Seka weight scale 193 calibrated to the nearest $0.1 \mathrm{~kg}$ after removing heavy clothes. The participants' height was 194 measured using the Seka measuring rod calibrated to the nearest $0.1 \mathrm{~cm}$. The participants took 195 off their shoes, stood erect and looked straight in the horizontal plane to measure their height. 196 The body mass index (BMI) was calculated as weight in kilograms divided by the square of 197 height in meters $\left(\mathrm{kg} / \mathrm{m}^{2}\right)$. Participants with a BMI of less than $18.5 \mathrm{~kg} / \mathrm{m}^{2}$ were considered 198 malnourished.

199

200 Household dietary diversity is the economic ability of a household to access a variety of foods 201 during the past seven days. Household dietary diversity was measured based on the dietary 202 measurement method (Kennedy, Ballard \& Dop, 2011; Swindale \& Bilinksy, 2006). Twelve 203 questions were used to assess dietary diversity. Participants were asked to report the frequency of 204 consumption of each of the following 12 food groups: (1) cereals; (2) roots and tubers; (3) pulses 205 and legumes/nuts; (4) vegetables; (5) fruits; (6) meat and poultry; (7) eggs; (8) fish and seafood; 206 (9) milk and milk products; (10) oils and fats; (11) sugar and sweets; and (12) miscellaneous. 207 Irrespective of the frequency, participants received ' 1 ' point if they consumed at least once 208 during the last seven days of the foods within each subgroup, and ' 0 ' points if they never 209 consumed the food. The household dietary diversity score (HDDS) was constructed as the sum 210 of some food groups consumed over the past week, ranging from 0 to 12 . A high value indicated 211 a diversified diet. The mean household dietary diversity score in the study subjects was 212 categorized as adequate if the dietary diversity score is nine or above, and inadequate, when the 213 diversity score is below nine.

214

215 Asset possession refers to a household's possession of assets elicited by asking participants a 216 series of 13 questions about household assets and housing characteristics such as housing quality 
217 (floor, walls and roof material), source of drinking water, type of toilet facility, presence of 218 electricity, type of cooking fuel, and ownership of modern household durable goods and 219 livestock (e.g. bicycle, television, radio, motorcycle, telephone, refrigerator, mattress, bed and 220 mobile phone). Following the method of Filmer and Pritchett (Filmer \& Pritchett, 2001), 221 principal components analysis was applied to define the asset wealth index among the PLWHA, 222 and based on wealth index score participants were sorted into three quintiles of relative asset 223 lower, middle and upper. A high value indicates more asset possession.

\section{Data analyses}

To assess factors associated with non-adherence to ART, binary adherence variables using data 227 from VAS was created. Both descriptive and analytic statistics were used. Binary logistic 228 regression analysis was used to find associations between the independent variables and the outcome variable. The Chi-square test of independence was used to find factors for not taking medication. All the variables showing a significant association in a binary analysis at $\mathrm{p}<0.25$ were entered to multivariable logistic regression to identify factors which have statistically significant association. In the final multivariate analysis, the test was two-sided and p-value $<0.05$ was considered statistically significant. All statistical analyses were conducted in IBM SPSS Statistics for Windows, Version 24.0 (IBM Corporation, Armonk, NY, USA).

\section{Ethical approval and consent to participate}

Before the study begins, ethical clearance was obtained from the Health Studies Higher Degrees Committee of the College of Human Sciences at the University of South Africa (UNISA) (REC 012714-039 NHERC). Further, permission to conduct the study (ethical clearance) was sought after authorised cooperation letter was written from UNISA Ethiopia regional learning centre to Benishangul Gumuz Regional State Health Bureau (BG-RHB) and thus obtained the ethical clearance. A support letter to conduct the study among the selected health facilities in the region was further written to those health facilities by BGR-RHB. Institutional consent and permission to conduct an interview with PLWHA among the selected health facilities were sought. Authorities at the study sites were assured that any information that the researcher came across during the conduct of the research was not be disclosed to any interest groups that could jeopardize the 
248 of the institutions, which has the right to terminate the study if the safety and confidentiality of 249 participants might be compromised. All participants provided written informed consent to indicate 250 their voluntary participation in the study before administering any instrument. The researchers 251 ensured that participants understood their rights of voluntary participation, anonymity and 252 confidentiality. ART follow-up records were retrieved by the health providers working in the ART 253 units, and personal information of the participants was kept confidential.

254

\section{RESULTS}

256 Three hundred and ninety-four study participants were recruited for this study. Only four 257 participants declined or terminated to participate into the study. The majority $(80 \%)$ of the 258 participants were aged between 25 and 44 years. The women participants constituted (66.4\%) of 259 the total participants. Nearly (50\%) of the participants were married and an equal number of the 260 participants were divorced, widowed or single. About (36.4\%) of them never attended school, 261 while only (4\%) attended college/university. The majority of the participants (91\%) lived in 262 urban areas. Table 2 shows the characteristics of the study participants.

263

264

In terms of socioeconomic characteristics, most of the participants were poor as measured by the 265 wealth index, a proxy measure for asset possession. About (60\%) of them were in the lower asset 266 tertiles. More than a quarter of them were unemployed (31\%). A large number of the participants 267 (67.7\%) lived on a poor mean monthly income of 1,260 Ethiopian Birr (equivalent to US\$45), below the World Bank poverty threshold of US\$1.90/day (The World Bank Group, 2019). The 269 vast majority of the study participants (76\%) were food insecure and $(60 \%)$ had a BMI of less

270 than $18.5 \mathrm{~kg} / \mathrm{m}^{2}$. The mean CD4 count was $559(\mathrm{SD}=319.6) \mathrm{cells} / \mathrm{mm}^{3}$, with a range of 60 to $1,914 \mathrm{cell} / \mathrm{mm}^{3}$. More than a quarter of them (33.6\%) suffered from frequent opportunistic 272 infection in the last three months.

273

274 Based on a 30-day adherence measurement, (39.7\%) of the study participants were found non275 adherent to ART. Of the food insecure participants, more than half (51.4\%) was non-adherent; 276 while (47.2\%) of malnourished PLWHA, those whose BMI is below $18.5 \mathrm{~kg} / \mathrm{m}^{2}$ was non277 adherent to ART. 


\section{Factors associated with non-adherence to antiretroviral therapy}

280 As presented in Table 3, in the binary logistic regression analysis age below 25 years, marital 281 status, urban residential area, never been to school, lack of employment, food insecurity, BMI

282 below $18.5 \mathrm{~kg} / \mathrm{m}^{2}$, household dietary diversity, poor asset possession, CD4 cell count below 350 $283 \mathrm{cell} / \mathrm{mm}^{3}$, and history of opportunistic infections were found associated with non-adherence to 284 ART. But subsequent multivariate logistic regression analysis showed age below 25 years, lack 285 of employment, food insecurity, malnutrition and opportunistic infections were among the 286 factors associated with the factors in non-adherence to ART.

287

288

Age groups of less than 25 years were found to be four-fold non-adherent to ART in comparison 289 with older age groups (AOR: 4.30, 95\% CI: 1.39, 3.35; $\mathrm{p}=0.011$ ). Urban residential area is also 290 found contributing for non-adherence to ART (AOR: 2.78, CI: 1.23, 7.09, p=0.043). The odds of non-adherence to ART among unemployed PLWHA were almost twice higher than their peers who were employed (AOR: 1.75, 95\% CI: 1.05, 2.91; $\mathrm{p}=0.032$ ). Food insecurity was the other socioeconomic factor strongly found impeding ART adherence (AOR: 2.67, 95\% CI: 7.59, 8.97; $\mathrm{p}<0.0001$ ), and malnutrition was among factors deterring PLWHA to attain the required $\geq 95 \%$ ART adherence level (AOR: 1.55, 95\% CI: 1.94, 2.56; $\mathrm{p}=0.027)$. Recurrent episodes of opportunistic infection (AOR: $1.81,95 \% \mathrm{CI}: 1.11,2.97 ; \mathrm{p}=0.018)$ was a clinical factor contributing to non-adherence to ART.

298

\section{Reasons for missing medication}

300

The prevalence of non-adherence to ART in this study was found to be (39.7\%). Among these,

301 $(83 \%)$ of them missed twice a month while $(4.4 \%)$ missed three times or more a month. Four reasons were reported by the study participants as important reasons for missing their

303 medications: (i) demanding work or household responsibilities (33\%), (ii) ran out of medication (34\%), (iii) unable to take without food (22\%), and (iv) forgetfulness (11\%). Table 4 shows selfreported reasons for missing medications.

306

\section{DISCUSSION}

In the current study, the factors associated with non-adherence to ART among PLWHA in 
310 adherence, with only $60.3 \%$ of our study participants remaining adherent to ART signposts the

311 requirements of more efforts towards commitment to and realization of a 90-90-90 HIV

312 treatment initiative. The study found age groups below 25 years were non-adherent to ART.

313 Analogous to this finding, the results of a meta-analysis study (Ghidei et al., 2013) showed a

314 higher risk of non-adherence among young PLWHA while older PLWHA had reduced risk of

315 non-adherence to ART. Another study in Canada found a higher proportion of non-adherence

316 among young PLWHA (Hadland et al., 2012). Youths are willing to engage in greater risky

317 sexual behaviors and may also be more likely to assume the risks of poor HIV medication

318 compliance, thus youth tailored behavioral change interventions that address the special

319 emotional and developmental concerns of younger PLWHA could be designed.

320

321 Strong plausible evidence of the association between non-adherence to ART and food insecurity

322 was found. Food insecure PLWHA were found twice more likely non-adherence to ART than

323 their food secure counterparts. Studies in both developing and developed countries have

324 culminated the strong association between non-adherence to ART and food insecurity effects.

325 For example, studies in Lake Victoria,Kenya (Nagata et al., 2012) and in Atlanta, USA

326 (Pellowski et al., 2016) showed that food insecure PLWHA miss doses of their daily medication.

327 Similarly, studies in Jimma, southwest Ethiopia (Tiyou et al., 2012), and Congo (Musumari et

328 al., 2014), and established a strong association between non-adherence to ART and food

329 insecurity. Since non-adherence to ART can risk developing viral resistance (Weiser et al., 2012;

330 Musumari et al., 2014) and food insecurity poses a significant challenge to the HIV/AIDS

331 response (Pellowski et al., 2016; Federal Ministry of Health of Ethiopia, 2015; Kalichman et al.,

332 2014).

333

334 In similar with the findings of other studies in Ethiopia (Berhe, Tegabu \& Alemayehu, 2013), the 335 current study found malnourished PLWHA were non-adherent to ART. This is also reported in

336 another matched case-control study in the Central Tigray Zone, Ethiopia that revealed

337 malnutrition was among the independent factors associated with lack of adherence to ART

338 (Weldehaweria et al., 2017). Absence of nutritional support fuels the synergistic co-existence of

339 HIV and malnutrition that has a perverse effect on ART adherence and the wellbeing of PLWHA

340 (Mekuria et al., 2015; Sicotte et al., 2014; Berhe, Tegabu \& Alemayehu, 2013). Therefore, 
341 nutritious food support is highly regarded as a viable option to increase weight gain (Audain et

342 al., 2015) and improve treatment outcome (Chaiyachati et al., 2014:Tiyou et al., 2012).

343

344 Our findings are similar to the study by Nachega et al., who found a strong association between

345 non-adherence to ART and lack of employment among PLWHA living both in low-income and

346 in high-income countries (Nagata et al., 2012). In opposition to this finding, unemployed

347 PLWHA in Nigeria had better ART adherence than employed people and rarely missed their

348 ART medications (Okoronkwo et al., 2013). The possible explanation for adherence among

349 unemployed PLWHA might be time freedom to take their medications without forgetting being a

350 concern. Also, they are more privileged to take their medications freely without any

351 psychological impacts that put them under stress such as the workplace environment

352 (Okoronkwo et al., 2013). Education status, dietary diversity and asset possession were among

353 the alterable socioeconomic factors found influencing adherence to ART, thus developing

354 effective adherence interventions to such alterable barriers are important in achieving an

355 optimum adherence level.

356

357 Opportunistic infections were found to affect the treatment outcome of PLWHA. According to 358 the results of this study, those who suffered recurrent illness within the last three months were 359 twice more likely to miss their treatment and be non-adherent to ART. This finding is consistent 360 with the findings of other studies that reported the presence of a significant association between 361 treatment for HIV and other infections and adherence to ART (Eyassu, Mothiba \& Mbambo-

362 Kekana, 2016). Corresponding to this finding, non-adherence to ART as a result of opportunistic 363 infection was reported among PLWHA in Yaounde, Cameroon (Fonsah et al., 2017) and the

364 Republic of Korea (Kim et al., 2018). The reason for non-adherence to ART among sick 365 PLWHA include the pill burden and poor absorption (Fonsah et al., 2017; Eyassu, Mothiba \& 366 Mbambo-Kekana, 2016).

367

368 Unlike the study of Schafter et al (Schafer et al., 2017), the findings of the current study reveals 369 urban residential area as a risk factor for non-adherence to ART. This findings are consistent 370 with the evidence that urban residences, as a result of dynamic socioeconomic alteration, may 371 lack the desired adherence level (Belayihun \& Negus, 2015). Similar to this finding, a study at 
372 Gonder University in northwest Ethiopia revealed that urban residential areas are associated with

373 factors of non-adherence to ART (Molla et al., 2018). To alleviate the adherence issues both in

374 urban and rural setups, a robust and sustainable response has to be foresighted, including using

375 community volunteers to re-engage patients in care and helping them to remain in care, and

376 empowering PLWHA in rural areas to regularly visit their healthcare provider (Kaihin et al.,

377 2015; Campbell et al., 2012).

378

379 The current study has several limitations: first, even if an attempt was made to minimize social 380 desirability bias, it might be subjected to recall and social desirability biases as ART adherence,

381 food security and dietary diversity were assessed based on the self-reported measure. Second, the

382 study design was cross-sectional in nature and hence cannot be used to determine causality.

383 Malnutrition can be both a cause and effect of non-adherence to ART. Hence, future longitudinal

384 studies are warranted to ascertain the causal directions of these variables.

385

386 CONCLUSIONS

387 The current study provides empirical findings on the factors associated with non-adherence to 388 ART and the extent of non-adherence in Benishangul-Gumuz. The magnitude of non-adherence 389 is as high as (39.7\%) in the region. High prevalence of non-adherence is strongly associated with 390 young age below 25 years, urban residential area, lack of employment, food insecurity, 391 malnutrition and opportunistic infections. Therefore, improving ART adherence requires the 392 adoption of innovative youth-centered adherence enhancing strategies, creation of employment 393 opportunities, devising follow-up and mitigation of recurrent opportunistic illness, and 394 integrating nutrition and food security interventions with the HIV/AIDS program that can be 395 implemented across all setups through the multisectoral approach to bridge the resource gap and 396 improve the treatment outcome across all setups.

397

\section{Acknowledgements}

399 We are grateful to all the research assistants, the data entry clerks and the PLWHA who 400 voluntarily participated in the survey; and to the University of South Africa for the support 401 provided to us.

402 


\section{Competing interests}

404 The authors declare no conflicts of interest.

405

406

\section{Authors' contributions}

407 Fikadu Tadesse designed and implemented the field research, performed the statistical analyses 408 and drafted the manuscript. Azwihangwisi Mavhandu-Mudzusi reviewed the manuscript. Both 409 authors contributed to the interpretation of the data and critically revising the paper, and agree to 410 be accountable for all aspects of the work.

411

\section{List of abbreviations}

413 AIDS: Acquired Immune Deficiency Syndrome; ART: Antiretroviral Treatment; BG-RHB:

414 Benishangul-Gumuz Regional State Health Bureau; BMI: Body Mass Index; HDDS: Household 415 Dietary Diversity score; HFIAS: Household Food Insecurity Access Scale score; HIV: Human 416 Immunodeficiency Virus; PLWHA: people living with HIV and AIDS; UNISA: University of 417 South Africa; United Nations World Food Programme (WFP)

418

\section{Availability of data}

420 The raw data has been provided in the Supplemental Files.

421

422 Funding

423 The authors received no funding for this work.

\section{REFERENCES}

Abera A, Fenti B, Tesfaye T, Balcha F. 2015. Factors Influencing Adherence to Antiretroviral Therapy among People Living With HIV/AIDS at ART Clinic in Jimma University Teaching Hospital, Southwest Ethiopia. Journal of Pharmacological Reports 1:1-6.

Alagaw A, Godana W, Taha M, Dejene T. 2013. Factors Associated with Antiretroviral Treatment Adherence among Adult Patients in Wolaita Soddo Hospital. Journal of Tropical Diseases \& Public Health 1:1-7. DOI: 10.4172/2329-891X.1000125. 
432 Audain KA, Zotor FB, Amuna P, Ellahi B. 2015. Food supplementation among HIV-infected

433

434

435

436

437

438

439

440

441

442

443

444

445

446

447

448

449

450

451

452

453

454

455

456

457

458

459

460

461

adults in Sub-Saharan Africa: impact on treatment adherence and weight gain. The Proceedings of the Nutrition Society 74:517-525. DOI: 10.1017/S0029665115000063.

Bangsberg DR. 2006. Less Than 95\% Adherence to Nonnucleoside Reverse-Transcriptase Inhibitor Therapy Can Lead to Viral Suppression. Clinical Infectious Diseases 43:939941. DOI: $10.1086 / 507526$.

Basti BD, Mahesh V, Bant DD, Bathija GV. 2017. Factors affecting antiretroviral treatment adherence among people living with human immunodeficiency virus/acquired immunodeficiency syndrome: A prospective study. Journal of Family Medicine and Primary Care 6:482. DOI: 10.4103/2249-4863.222014.

Belayihun B, Negus R. 2015. Antiretroviral Treatment Adherence Rate and Associated Factors among People Living with HIV in Dubti Hospital, Afar Regional State, East Ethiopia. International Scholarly Research Notices 2015. DOI: 10.1155/2015/187360.

Berhe N, Tegabu D, Alemayehu M. 2013. Effect of nutritional factors on adherence to antiretroviral therapy among HIV-infected adults: a case control study in Northern Ethiopia. BMC Infectious Diseases 13:233. DOI: 10.1186/1471-2334-13-233.

Byrd KK, Hou JG, Hazen R, Kirkham H, Suzuki S, Clay PG, Bush T, Camp NM, Weidle PJ, Delpino A, Patient-centered HIV Care Model Team. 2019. Antiretroviral Adherence Level Necessary for HIV Viral Suppression using Real-World Data. Journal of Acquired Immune Deficiency Syndromes (1999). DOI: 10.1097/QAI.0000000000002142.

Campbell C, Skovdal M, Mupambireyi Z, Madanhire C, Nyamukapa C, Gregson S. 2012. Building adherence-competent communities: Factors promoting children's adherence to anti-retroviral HIV/AIDS treatment in rural Zimbabwe. Health \& Place 18:123-131. DOI: 10.1016/j.healthplace.2011.07.008.

Chaiyachati KH, Ogbuoji O, Price M, Suthar AB, Negussie EK, Bärnighausen T. 2014. Interventions to improve adherence to antiretroviral therapy: a rapid systematic review. AIDS (London, England) 28 Suppl 2:S187-204. DOI: 10.1097/QAD.0000000000000252.

Chauhan CK, Lakshmi PVM, Sagar V, Sharma A, Arora SK, Kumar R. 2019. Primary HIV Drug Resistance among Recently Infected Cases of HIV in North-West India. AIDS Research and Treatment 2019:1-8. DOI: 10.1155/2019/1525646.

Peer) reviewing PDF | (2019:08:39967:4:0:NEW 2 Jan 2020) 
462 Chesney MA, Ickovics JR, Chambers DB, Gifford AL, Neidig J, Zwickl B, Wu AW, Patient

463

464

465

466

467

468

469

470

471

472

473

474

475

476

477

478

479

480

481

482

483

484

485

486

487

488

489

490

491

Care Committee \& Adherence. 2000. Self-reported adherence to antiretroviral medications among participants in HIV clinical trials: The AACTG Adherence Instruments. AIDS Care 12:255-266. DOI: 10.1080/09540120050042891.

Chkhartishvili N, Rukhadze N, Svanidze M, Sharvadze L, Dehovitz JA, Tsertsvadze T, McNutt L-A, del Rio C. 2014. Evaluation of multiple measures of antiretroviral adherence in the Eastern European country of Georgia. Journal of the International AIDS Society 17. DOI: 10.7448/IAS.17.1.18885.

Coates J, Swindale A, Bilinsky P. 2007. Household Food Insecurity Access Scale (HFIAS) for Measurement of Food Access: Indicator Guide: Version 3: (576842013-001). DOI: 10.1037/e576842013-001.

Dalhatu I, Onotu D, Odafe S, Abiri O, Debem H, Agolory S, Shiraishi RW, Auld AF, Swaminathan M, Dokubo K, Ngige E, Asadu C, Abatta E, Ellerbrock TV. 2016. Outcomes of Nigeria's HIV/AIDS Treatment Program for Patients Initiated on Antiretroviral Treatment between 2004-2012. PLOS ONE 11:e0165528. DOI: 10.1371/journal.pone.0165528.

Deribew A, Biadgilign S, Deribe K, Dejene T, Tessema GA, Melaku YA, Lakew Y, Amare AT, Bekele T, Abera SF, Kumsa A, Assefa Y, Glenn SD, Carter A, Misganaw A, Wang H. 2019. The Burden of HIV/AIDS in Ethiopia from 1990 to 2016: Evidence from the Global Burden of Diseases 2016 Study. 29:10.

Eyassu MA, Mothiba TM, Mbambo-Kekana NP. 2016. Adherence to antiretroviral therapy among HIV and AIDS patients at the Kwa-Thema clinic in Gauteng Province, South Africa. African Journal of Primary Health Care \& Family Medicine 8. DOI: 10.4102/phcfm.v8i2.924.

Federal Ministry of Health of Ethiopia. 2015. Health Sector Transformation Plan 2015/16 2019/20 (2008-2012 EFY). Addis Ababa, Ethiopia: Goverment press.

Filmer D, Pritchett LH. 2001. Estimating wealth effects without expenditure data--or tears: an application to educational enrollments in states of India. Demography 38:115-132.

Finitsis DJ, Pellowski JA, Huedo-Medina TB, Fox MC, Kalichman SC. 2016. Visual analogue scale (VAS) measurement of antiretroviral adherence in people living with HIV (PLWH):

Peerj reviewing PDF | (2019:08:39967:4:0:NEW 2 Jan 2020) 
492

493

494

495

496

497

498

499

500

501

502

503

504

505

506

507

508

509

510

511

512

513

514

515

516

517

518

519

520

521

a meta-analysis. Journal of Behavioral Medicine 39:1043-1055. DOI: 10.1007/s10865016-9770-6.

Fonsah JY, Njamnshi AK, Kouanfack C, Qiu F, Njamnshi DM, Tagny CT, Nchindap E, Kenmogne L, Mbanya D, Heaton R, Kanmogne GD. 2017. Adherence to Antiretroviral Therapy (ART) in Yaoundé-Cameroon: Association with Opportunistic Infections, Depression, ART Regimen and Side Effects. PloS One 12:e170893. DOI: 10.1371/journal.pone.0170893.

G. Williams B, Lima V, Gouws E. 2011. Modelling the Impact of Antiretroviral Therapy on the Epidemic of HIV. Current HIV Research 9:367-382. DOI: $10.2174 / 157016211798038533$.

Ghidei L, Simone M, Salow M, Zimmerman K, Paquin AM, Skarf LM, Kostas T, Rudolph JL. 2013. Aging, Antiretrovirals, and Adherence: A Meta Analysis of Adherence among Older HIV-Infected Individuals. Drugs \& aging 30. DOI: 10.1007/s40266-013-0107-7.

Granich R, Kahn JG, Bennett R, Holmes CB, Garg N, Serenata C, Sabin ML, MakhloufObermeyer C, De Filippo Mack C, Williams P, Jones L, Smyth C, Kutch KA, Ying-Ru L, Vitoria M, Souteyrand Y, Crowley S, Korenromp EL, Williams BG. 2012. Expanding ART for Treatment and Prevention of HIV in South Africa: Estimated Cost and CostEffectiveness 2011-2050. PLoS ONE 7:e30216. DOI: 10.1371/journal.pone.0030216.

Hadland SE, Milloy M-J, Kerr T, Zhang R, Guillemi S, Hogg RS, Montaner JS, Wood E. 2012. Young Age Predicts Poor Antiretroviral Adherence and Viral Load Suppression Among Injection Drug Users. AIDS Patient Care and STDs 26:274-280. DOI: 10.1089/apc.2011.0196.

Hansana V, Sanchaisuriya P, Durham J, Sychareun V, Chaleunvong K, Boonyaleepun S, Schelp FP. 2013. Adherence to Antiretroviral Therapy (ART) among People Living With HIV (PLHIV): a cross-sectional survey to measure in Lao PDR. BMC Public Health 13:617. DOI: $10.1186 / 1471-2458-13-617$.

Iacob SA, Iacob DG, Jugulete G. 2017. Improving the Adherence to Antiretroviral Therapy, a Difficult but Essential Task for a Successful HIV Treatment-Clinical Points of View and Practical Considerations. Frontiers in Pharmacology 8:831. DOI: 10.3389/fphar.2017.00831. 
522 Kaihin R, Kasatpibal N, Chitreechuer J, Grimes RM. 2015. Effect of an Empowerment

523

524

525

526

527

528

529

530

531

532

533

534

535

536

537

538

539

540

541

542

543

544

545

546

547

548

549

550

551

552 Intervention on Antiretroviral Drug Adherence in Thai Youth. Behavioral Medicine 41:186-194. DOI: 10.1080/08964289.2014.911717.

Kalichman SC, Grebler T, Amaral CM, McKerney M, White D, Kalichman MO, Cherry C, Eaton L. 2014. Food insecurity and antiretroviral adherence among HIV positive adults who drink alcohol. Journal of Behavioral Medicine 37:1009-1018. DOI: 10.1007/s10865-013-9536-3.

Karade S, Chaturbhuj DN, Sen S, Joshi RK, Kulkarni SS, Shankar S, Gangakhedkar RR. 2018. HIV drug resistance following a decade of the free antiretroviral therapy programme in India: A review. International Journal of Infectious Diseases 66:33-41. DOI: 10.1016/j.jijid.2017.10.020.

Kennedy G, Ballard T, Dop M-C. 2011. Guidelines for measuring household and individual dietary diversity. Rome: FAO.

Kim J, Lee E, Park B-J, Bang JH, Lee JY. 2018. Adherence to antiretroviral therapy and factors affecting low medication adherence among incident HIV-infected individuals during 2009-2016: A nationwide study. Scientific Reports 8:3133. DOI: 10.1038/s41598-01821081-x.

Liping M, Peng X, Haijiang L, Lahong J, Fan LH, Yuhua R. 2015. Quality of Life of People Living with HIV/AIDS: A Cross-Sectional Study in Zhejiang Province, China. In: PloS one. DOI: 10.1371/journal.pone.0135705.

Mekuria LA, Sprangers MAG, Prins JM, Yalew AW, Nieuwkerk PT. 2015. Health-related quality of life of HIV-infected adults receiving combination antiretroviral therapy in Addis Ababa. AIDS care 27:934-945. DOI: 10.1080/09540121.2015.1020748.

Mohammed AY, Ahmed MB, Tefera TB. 2015. Assessment of Factors Affecting Art Adherence among People Living with Human Immune Virus in Bale Robe Hospital, South East Ethiopia. American Journal of Public Health Research 3:60-67. DOI: 10.12691/ajphr-3$2-5$.

Molla AA, Gelagay AA, Mekonnen HS, Teshome DF. 2018. Adherence to antiretroviral therapy and associated factors among HIV positive adults attending care and treatment in University of Gondar Referral Hospital, Northwest Ethiopia. BMC Infectious Diseases 18. DOI: $10.1186 / \mathrm{s} 12879-018-3176-8$. 
553 Musumari PM, Wouters E, Kayembe PK, Kiumbu Nzita M, Mbikayi SM, Suguimoto SP, 554 Techasrivichien T, Lukhele BW, El-saaidi C, Piot P, Ono-Kihara M, Kihara M. 2014. 555

556

557

558

559

560

561

562

563

564

565

566

567

568

569

570

571

572

573

574

575

576

577

578

579

580

581

582

583

Food Insecurity Is Associated with Increased Risk of Non-Adherence to Antiretroviral Therapy among HIV-Infected Adults in the Democratic Republic of Congo: A CrossSectional Study. PLoS ONE 9:e85327. DOI: 10.1371/journal.pone.0085327.

Nachega J, C. Marconi V, U. van Zyl G, M. Gardner E, Preiser W, Y. Hong S, J. Mills E, Gross R. 2011. HIV Treatment Adherence, Drug Resistance, Virologic Failure: Evolving Concepts. Infectious Disorders - Drug Targets 11:167-174. DOI:

$10.2174 / 187152611795589663$.

Nagata JM, Magerenge RO, Young SL, Oguta JO, Weiser SD, Cohen CR. 2012. Social determinants, lived experiences, and consequences of household food insecurity among persons living with HIV/AIDS on the shore of Lake Victoria, Kenya. AIDS care 24:728736. DOI: $10.1080 / 09540121.2011 .630358$.

Nasuuna E, Kigozi J, Babirye L, Muganzi A, Sewankambo NK, Nakanjako D. 2018. Low HIV viral suppression rates following the intensive adherence counseling (IAC) program for children and adolescents with viral failure in public health facilities in Uganda. BMC Public Health 18:1048. DOI: 10.1186/s12889-018-5964-x.

Oguntibeju O. 2012. Quality of life of people living with HIV and AIDS and antiretroviral therapy. HIV/AIDS - Research and Palliative Care:117. DOI: 10.2147/HIV.S32321.

Okoronkwo I, Okeke U, Chinweuba A, Iheanacho P. 2013.Nonadherence Factors and Sociodemographic Characteristics of HIV-Infected Adults Receiving Antiretroviral Therapy in Nnamdi Azikiwe University Teaching Hospital, Nnewi, Nigeria. Available at https://www.hindawi.com/journals/isrn/2013/843794/ (accessed April 1, 2019). DOI: 10.1155/2013/843794.

Paterson DL, Swindells S, Mohr J, Brester M, Vergis EN, Squier C, Wagener MM, Singh N. 2000. Adherence to protease inhibitor therapy and outcomes in patients with HIV infection. Annals of Internal Medicine 133:21-30. DOI: 10.7326/0003-4819-133-1200007040-00004.

Pellowski JA, Kalichman SC, Cherry S, Conway-Washington C, Cherry C, Grebler T, Krug L. 2016. The Daily Relationship Between Aspects of Food Insecurity and Medication Adherence Among People Living with HIV with Recent Experiences of Hunger. Annals

Peer) reviewing PDF | (2019:08:39967:4:0:NEW 2 Jan 2020) 
584

585

586

587

588

589

590

591

592

593

594

595

596

597

598

599

600

601

602

603

604

605

606

607

608

609

610

611

612

613

614

of Behavioral Medicine: A Publication of the Society of Behavioral Medicine 50:844853. DOI: 10.1007/s12160-016-9812-X.

Peltzer K, Pengpid S. 2013. Socioeconomic Factors in Adherence to HIV Therapy in Low- and Middle-income Countries. Journal of Health, Population, and Nutrition 31:150-170.

Robbins RN, Spector AY, Mellins CA, Remien RH. 2014. Optimizing ART Adherence: Update for HIV Treatment and Prevention. Current HIV/AIDS reports 11:423-433. DOI: 10.1007/s11904-014-0229-5.

Samuel Edward K, Maseke Richard M, Basiliana E, Geofrey Nimrod S, Debora Charles K. 2018. Factors Influencing Adherence to Antiretroviral Therapy among HIV Infected Patients in Nyamagana-Mwanza, Northern Tanzania: A Cross Sectional Study. International Archives of Medical Microbiology 1. DOI: 10.23937/iamm-2017/1710002.

Schafer KR, Albrecht H, Dillingham R, Hogg RS, Jaworsky D, Kasper K, Loutfy M, MacKenzie LJ, McManus KA, Oursler KAK, Rhodes SD, Samji H, Skinner S, Sun CJ, Weissman S, Ohl ME. 2017. The Continuum of HIV Care in Rural Communities in the United States and Canada: What Is Known and Future Research Directions. Journal of acquired immune deficiency syndromes (1999) 75:35-44. DOI: 10.1097/QAI.0000000000001329.

Sicotte M, Langlois ÉV, Aho J, Ziegler D, Zunzunegui MV. 2014. Association between nutritional status and the immune response in HIV + patients under HAART: protocol for a systematic review. Systematic Reviews 3:9. DOI: 10.1186/2046-4053-3-9.

Swindale A, Bilinksy P. 2006. Household Dietary Diversity Score (HDDS) for Measurement of Household Food Access: Indicator Guide (Version 2). :15.

Tabachnick B, Fidell L. 2007. Using Multivariate Statistics (5th ed.). New York: Allyn and Bacon.

The Federal Democratic Republic of Ethiopia Ministry of Health. 2015. Health Sector Transformation Plan (HSTP) 2015/16 - 2019/20 (2008-2015). The Federal Democratic Republic of Ethiopia Ministry of Health.

The World Bank Group. 2019.Poverty Overview: Ethiopia. Available at https://www.worldbank.org/en/topic/poverty/overview (accessed April 8, 2019).

Tiyou A, Belachew T, Alemseged F, Biadgilign S. 2012. Food insecurity and associated factors among HIV-infected individuals receiving highly active antiretroviral therapy in Jimma zone Southwest Ethiopia. Nutrition Journal 11. DOI: 10.1186/1475-2891-11-51. 
615 UNAIDS. 2011. A new investment framework for the global HIV response.

616 UNAIDS. 2015.How AIDS changed everything - MDG6: 15 years, 15 lessons of hope from the $617 \quad$ AIDS response. Available at

618 http://www.unaids.org/en/resources/documents/2015/MDG6_15years-

619 15lessonsfromtheAIDSresponse (accessed April 6, 2019).

620 UNAIDS. 2017. UNAIDS DATA 2017.

621 UNAIDS. 2018.Global HIV \& AIDS statistics - 2018 fact sheet. Available at 622 http://www.unaids.org/en/resources/fact-sheet (accessed April 17, 2019).

623 US Department of Agriculture, Economic Research Service. 2019.Definitions of Food Security. $624 \quad$ Available at https://www.ers.usda.gov/topics/food-nutrition-assistance/food-security-in625 the-us/definitions-of-food-security.aspx (accessed April 8, 2019).

626 US National Library of Medicine. 2019.Malnutrition: Definition. Available at 627 https://medlineplus.gov/ency/article/000404.htm (accessed April 8, 2019).

628 Wang EA, McGinnis KA, Fiellin DA, Goulet JL, Bryant K, Gibert CL, Leaf DA, Mattocks K, 629 Sullivan LE, Vogenthaler N, Justice AC. 2011. Food Insecurity is Associated with Poor Virologic Response among HIV-Infected Patients Receiving Antiretroviral Medications. Journal of General Internal Medicine 26:1012-1018. DOI: 10.1007/s11606-011-1723-8.

Wasti SP, Simkhada P, Randall J, Freeman JV, van Teijlingen E. 2012. Factors Influencing Adherence to Antiretroviral Treatment in Nepal: A Mixed-Methods Study. PLoS ONE

635 7:e35547. DOI: 10.1371/journal.pone.0035547.

636

637

638

639

640

641

642

643

Weiser SD, Tsai AC, Gupta R, Frongillo EA, Kawuma A, Senkungu J, Hunt PW, Emenyonu NI, Mattson JE, Martin JN, Bangsberg DR. 2012. Food insecurity is associated with morbidity and patterns of healthcare utilization among HIV-infected individuals in a resource-poor setting. AIDS (London, England) 26:67-75. DOI: 10.1097/QAD.0b013e32834cad37.

Weldehaweria NB, Abreha EH, Weldu MG, Misgina KH. 2017. Psychosocial correlates of nutritional status among people living with HIV on antiretroviral therapy: A matched case-control study in Central zone of Tigray, Northern Ethiopia. PloS One 12:e0174082. DOI: 10.1371/journal.pone.0174082. 
644 World Health Organization. 2010. Antiretroviral drugs for treating pregnant women and 645 preventing HIV infection in infants: recommendations for a public health approach. 646 Geneva: World Health Organization.

647 Young S, Wheeler A, McCoy S, Weiser SD. 2014. A review of the role of food insecurity in 648 adherence to care and treatment among adult and pediatric populations living with HIV 649 and AIDS. AIDS and behavior 18:505-515. DOI: 10.1007/s10461-013-0547-4.

650

651 


\section{Table $\mathbf{1}$ (on next page)}

Study sites and sample contribution 
1

2 Table 1: Study sites and sample contribution

\begin{tabular}{lcc}
\hline \multicolumn{1}{c}{ Name of health facility } & $\begin{array}{c}\text { Accessible population } \\
(\mathrm{M})\end{array}$ & $\begin{array}{c}\text { Samples (frequency, \%) } \\
\mathrm{n}=\sum\left[\left(\frac{\boldsymbol{M}}{\boldsymbol{N}}\right) * \mathbf{3 9 4}\right]\end{array}$ \\
\hline Hospital A & 1079 & $156(40 \%)$ \\
Hospital B & 921 & $133(34)$ \\
Health Centre X & 275 & $40(10)$ \\
Health Centre Y & 251 & $37(9 \%)$ \\
Health centre Z & 195 & $28(7 \%)$ \\
Total (N) & 2721 & $394(100 \%)$ \\
\hline
\end{tabular}

\section{Note.}

$4 \mathrm{M}$, the number of peoples living with HIV and AIDS receiving ART at each health facilities; N, total number of

5 PLWHA receiving ART at the study sites during the study period; n, number of samples proportionally drawn from

6 each study site 
Table 2 (on next page)

Characteristics of study participants, $\mathrm{N}=390$ 
1 Table 2: Characteristics of study participants, $\mathbf{N}=\mathbf{3 9 0}$

\begin{tabular}{|c|c|c|}
\hline Characteristics & $\begin{array}{l}\text { Non-adherent to } \\
\text { ART } \\
(\mathrm{n}=155)\end{array}$ & $\begin{array}{l}\text { Adherent to } \\
\text { ART } \\
(\mathrm{n}=\mathbf{2 3 5})\end{array}$ \\
\hline \multicolumn{3}{|l|}{ Sociodemographic characteristics } \\
\hline \multicolumn{3}{|l|}{ Age } \\
\hline Less than 25 years & $19(12.0)$ & $14(6.0)$ \\
\hline $25-35$ years & $76(49.0)$ & $106(45.1)$ \\
\hline More than 35 years & $60(38.7)$ & $115(48.9)$ \\
\hline \multicolumn{3}{|l|}{ Gender: } \\
\hline Female & $110(71.0)$ & $149(63.4)$ \\
\hline Male & $45(29.0)$ & $86(36.6)$ \\
\hline \multicolumn{3}{|l|}{ Marital status: } \\
\hline Divorced/Widowed/Single & $67(43.2)$ & $128(54.5)$ \\
\hline Married & $88(56.8)$ & $107(45.5)$ \\
\hline \multicolumn{3}{|l|}{ Religious: } \\
\hline Christian & $117(75.5)$ & $184(78.3)$ \\
\hline Muslim & $38(24.5)$ & $51(21.7)$ \\
\hline \multicolumn{3}{|l|}{ Residence area: } \\
\hline Urban & $149(96.1)$ & $206(87.7)$ \\
\hline Rural & $6(3.9)$ & $29(12.3)$ \\
\hline \multicolumn{3}{|l|}{ Socioeconomic factors } \\
\hline \multicolumn{3}{|l|}{ Education level: } \\
\hline Never been to school & $57(36.8)$ & $85(36.2)$ \\
\hline Primary level & $69(44.5)$ & $97(41.3)$ \\
\hline Secondary level & $27(17.4)$ & $39(16.6)$ \\
\hline College/University level & $2(1.3)$ & $14(6.0)$ \\
\hline \multicolumn{3}{|l|}{ Employment status: } \\
\hline Unemployed & $70(45.2)$ & $52(22.1)$ \\
\hline Employed & $85(54.8)$ & $183(77.9)$ \\
\hline \multicolumn{3}{|l|}{ Monthly income (in Ethiopian Birr) } \\
\hline$<1750$ & $119(76.8)$ & $174(74)$ \\
\hline$\geq 1750$ & $36(23.2)$ & $61(26)$ \\
\hline \multicolumn{3}{|l|}{ Food security status: } \\
\hline Food insecure & $152(98.1)$ & $144(61.3)$ \\
\hline Food secure & $3(1.9)$ & $91(38.7)$ \\
\hline \multicolumn{3}{|l|}{ BMI score (in $\mathrm{kg} / \mathrm{m}^{2}$ ): } \\
\hline$<18.5$ & $111(71.6)$ & $124(52.8)$ \\
\hline$\geq 18.5$ & $44(28.4)$ & $111(47.2)$ \\
\hline \multicolumn{3}{|l|}{ Household dietary diversity: } \\
\hline Inadequate & $121(78.1)$ & $139(59.1)$ \\
\hline Adequate & $34(21.9)$ & $96(40.9)$ \\
\hline \multicolumn{3}{|l|}{ Household wealth index score } \\
\hline Lower & $76(49.0)$ & $158(67.2)$ \\
\hline Middle & $35(22.6)$ & $41(17.4)$ \\
\hline Upper & $44(28.4)$ & $36(15.3)$ \\
\hline \multicolumn{3}{|l|}{ Clinical features } \\
\hline \multicolumn{3}{|l|}{ Duration of ART initiation: } \\
\hline Less than 12 months & $13(8.4)$ & $24(10.2)$ \\
\hline $1-5$ years & $75(48.4)$ & $80(34.0)$ \\
\hline $5-10$ years & $56(36.1)$ & $112(47.7)$ \\
\hline$>10$ years & $11(7.1)$ & $19(8.1)$ \\
\hline
\end{tabular}


CD4 count (in Cell $/ \mathrm{mm}^{3}$ ): $<350$

350-500

$54(34.8)$

26 (16.8)

$54(23.0)$

$>501$

75 948.4)

55 (23.4)

History of opportunistic infections in the last

$126(53.6)$ three months:

Yes

$76(49.0)$

$55(23.4)$

No

$79(51.0)$

$180(76.6)$

2 Note.

$3 \mathrm{n}$, frequency in number; \%, percentage; 


\section{Table 3 (on next page)}

Bivariable and multivariable analysis of factors associated with non-adherence to ART 
1 Table 3: Bivariable and multivariable analysis of factors associated with non-adherence to

2 ART among peoples living with HIV and AIDS attending antiretroviral therapy in

3 Benishangul Gumuz Region, Ethiopia, 2019

\begin{tabular}{|c|c|c|c|c|c|c|}
\hline \multirow{2}{*}{ Characteristics } & \multicolumn{3}{|c|}{ Bivariable regression analysis } & \multicolumn{3}{|c|}{ Multivariable regression analysis } \\
\hline & COR & $95 \%$ CI & p-value & AOR & $95 \% \mathrm{CI}$ & p-value \\
\hline \multicolumn{7}{|l|}{$\begin{array}{l}\text { Sociodemographic } \\
\text { characteristics } \\
\text { Age }\end{array}$} \\
\hline \multirow{3}{*}{$\begin{array}{l}\text { Less than } 25 \text { years } \\
25-35 \text { years } \\
\text { More than } 35 \\
\text { years }\end{array}$} & 2.6 & {$[1.22,5.55]$} & 0.013 & 4.30 & {$[1.39,3.35]$} & 0.011 \\
\hline & 1.4 & {$[0.90,2.10]$} & 0.157 & 1.23 & {$[0.75,2.02]$} & 0.411 \\
\hline & Ref & & & & & \\
\hline \multicolumn{7}{|l|}{ Gender: } \\
\hline Female & 0.70 & {$[0.46,1.10]$} & 0.120 & 1.09 & {$[0.63 .1 .09]$} & 0.67 \\
\hline Male & Ref & & & & & \\
\hline \multicolumn{7}{|l|}{ Marital status: } \\
\hline $\begin{array}{l}\text { Divorced/Widowed/ } \\
\text { Single }\end{array}$ & 1.60 & {$[1.04,2.36]$} & 0.030 & 0.63 & {$[0.39,1.01]$} & 0.054 \\
\hline Married & Ref & & & & & \\
\hline \multicolumn{7}{|l|}{ Religious: } \\
\hline Christian & 1.17 & {$[0.71,1.90]$} & 0.520 & & & \\
\hline Muslim & Ref & & & & & \\
\hline \multicolumn{7}{|l|}{ Residence area: } \\
\hline Urban & 3.50 & {$[1.42,8.60]$} & 0.007 & 2.78 & {$[1.23,7.09]$} & 0.043 \\
\hline Rural & Ref & & & & & \\
\hline \multicolumn{7}{|l|}{ Socioeconomic factors } \\
\hline \multicolumn{7}{|l|}{ Education level: } \\
\hline $\begin{array}{l}\text { Never been to } \\
\text { school }\end{array}$ & 4.70 & {$[1.03,21.0]$} & 0.046 & 1.07 & {$[0.17,6.71]$} & 0.38 \\
\hline Primary level & 4.90 & {$[1.1,22.0]$} & 0.038 & 1.44 & {$[0.23,0.89]$} & 0.63 \\
\hline Secondary level & 4.80 & {$[1.02,23]$} & 0.047 & 1.42 & {$[0.21,9.46]$} & 0.71 \\
\hline $\begin{array}{l}\text { College/University } \\
\text { level }\end{array}$ & Ref & & & & & \\
\hline \multicolumn{7}{|l|}{ Employment status: } \\
\hline Unemployed & 2.89 & {$[1.86,4.50]$} & $<0.001$ & 1.75 & {$[1.05,2.91]$} & 0.032 \\
\hline Employed & Ref & & & & & \\
\hline \multicolumn{7}{|l|}{ Monthly income (in } \\
\hline \multicolumn{7}{|l|}{ Ethiopian Birr) } \\
\hline$<1750$ & 0.86 & {$[0.54,1.39]$} & 0.540 & & & \\
\hline$\geq 1750$ & Ref & & & & & \\
\hline \multicolumn{7}{|l|}{ Food security status: } \\
\hline Food insecure & 3.2 & {$[9.9,11.3]$} & $<0.0001$ & 2.67 & {$[7.59,8.97]$} & $<0.0001$ \\
\hline Food secure & Ref & & & & & \\
\hline \multicolumn{7}{|l|}{ BMI score (in $\mathrm{kg} / \mathrm{m}^{2}$ ): } \\
\hline$<18.5$ & 2.3 & {$[2.47,4.48]$} & $<0.0001$ & 1.55 & {$[1.94,2.56]$} & 0.027 \\
\hline$\geq 18.5$ & Ref & & & & & \\
\hline \multicolumn{7}{|l|}{ Household dietary diversity: } \\
\hline Inadequate & 2.5 & {$[1.60,3.90]$} & $<0.0001$ & 0.93 & {$[0.51,1.68]$} & 0.81 \\
\hline Adequate & Ref & & & & & \\
\hline
\end{tabular}


score

$\begin{array}{lllllll}\text { Lower } & 1.8 & {[1.05,3.01]} & 0.03 & 0.63 & {[0.33,1.13]} & 0.12 \\ \text { Middle } & 2.5 & {[1.51,4.27]} & 0.00 & 0.72 & {[0.35,1,47]} & 0.36 \\ \text { Upper } & \text { Ref } & & & & & \end{array}$

Clinical features

Duration of ART initiation:

$\begin{array}{llll}\text { Less than } 12 \text { months } & 0.94 & {[0.34,2.50]} & 0.890 \\ \text { 1-5 years } & 1.60 & {[0.72,3.60]} & 0.240 \\ \text { 5-10 years } & 0.86 & {[0.39,1.90]} & 0.720 \\ >10 \text { years } & \text { Ref } & & \end{array}$

CD4 count (in Cell $/ \mathrm{mm}^{3}$ ):

$\begin{array}{ll}<350 & 1.68 \\ 350-500 & 0.79\end{array}$

$\begin{array}{llllll}1.68 & {[1.10,2.60]} & 0.032 & 1.1 & {[0.57,1,78]} & 0.92\end{array}$

$\begin{array}{llllll}0.79 & {[0.46,1.40]} & 0.410 & 0.77 & {[0.39,1.46]} & 0.42\end{array}$

History of opportunistic

Ref

infections in the last three months:

Yes $\quad 3.20$

3.20

$[2.10,4.90]$

$<0.001$

$1.81 \quad[1.11,2.97]$

0.018

4 Note.

5 COR: crude odds ratio, AOR: adjusted odds ratio, OR: odds ratio, CI: confidence interval; Ref: reference

6 


\section{Table 4(on next page)}

Self-reported reason for missing ART 
1 Table 3: Self-reported reason for missing ART among peoples living with HIV and AIDS

2 attending antiretroviral therapy in Benishangul Gumuz Region, Ethiopia, 2019

\begin{tabular}{lllll}
\hline Characteristics & Frequency & Percent (\%) & $\mathbf{X}^{\mathbf{2}}$ & p-value \\
\hline ART adherence: & 235 & 60.3 & & \\
$\quad$ Adherent & 135 & 39.7 & & \\
$\quad$ Non-adherent & & & & \\
Reasons for not taking medication in the last seven days: & & 33.0 & & \\
$\quad$ Demanding work or household responsibilities & 44 & 34.0 & 0.009 \\
$\quad$ Ran out of medication & 46 & 22.0 & & \\
$\quad$ Unable to take without food & 30 & 11.0 & & \\
$\quad$ Forgetfulness & 15 & & & \\
Frequency of missing in the last seven days: & 112 & 83.0 & & \\
$\quad$ Two times & 17 & 12.043 & & \\
$\quad$ Three times & 6 & 4.4 & &
\end{tabular}

VAS adherence score:

$\mathrm{M}=86.40$

$\mathrm{SD}=14.94$

3

4 Notes.

$5 \quad \mathrm{X}^{2}$, Chi-square test; VAS, Visual Analogue Scale

6 